Nat. Hazards Earth Syst. Sci., 17, 1319-1336, 2017

https://doi.org/10.5194/nhess-17-1319-2017

(C) Author(s) 2017. This work is distributed under

the Creative Commons Attribution 3.0 License.

\title{
Spatiotemporal variability of lightning activity in Europe and the relation to the North Atlantic Oscillation teleconnection pattern
}

\author{
David Piper ${ }^{1,2}$ and Michael Kunz ${ }^{1,2}$ \\ ${ }^{1}$ Institute of Meteorology and Climate Research (IMK), Karlsruhe Institute of Technology (KIT), Karlsruhe, Germany \\ ${ }^{2}$ Center for Disaster Management and Risk Reduction Technology (CEDIM), Karlsruhe, Germany \\ Correspondence to: Michael Kunz (michael.kunz@kit.edu)
}

Received: 23 January 2017 - Discussion started: 26 January 2017

Revised: 2 June 2017 - Accepted: 28 June 2017 - Published: 8 August 2017

\begin{abstract}
Comprehensive lightning statistics are presented for a large, contiguous domain covering several European countries such as France, Germany, Austria, and Switzerland. Spatiotemporal variability of convective activity is investigated based on a 14-year time series (2001-2014) of lightning data. Based on the binary variable thunderstorm day, the mean spatial patterns of lightning activity and regional peculiarities regarding seasonality are discussed. Diurnal cycles are compared among several regions and evaluated with respect to major seasonal changes. Further analyses are performed regarding interannual variability and the impact of teleconnection patterns on convection.

Mean convective activity across central Europe is characterized by a strong northwest-to-southeast gradient with pronounced secondary features superimposed. The zone of maximum values of thunderstorm days propagates southwestward along the southern Alpine range from April to July. Diurnal cycles vary substantially between both different months and regions, particularly regarding the incidence of nighttime lightning. The North Atlantic Oscillation (NAO) is shown to have a significant impact on convective activity in several regions, which is primarily caused by variations of the largescale lifting pattern in both NAO phases. This dynamical effect is partly compensated for by thermodynamical modifications of the pre-convective environment. The results point to a crucial role of large-scale flow in steering the spatiotemporal patterns of convective activity.
\end{abstract}

\section{Introduction}

Among the damage caused by lightning strikes, convectionrelated weather phenomena such as strong wind gusts, heavy rain, hail, and tornadoes often lead to major economic losses and pose a significant threat to human life (e.g., Kunz and Puskeiler, 2010; Peyraud, 2013; Piper et al., 2016). In several European countries and regions such as Switzerland and southern Germany, the largest share of losses by natural hazards is related to severe convective storms (e.g., Punge et al., 2014; Puskeiler et al., 2016). Intense thunderstorm events may also occur in regions that are generally characterized by a rather weak convective activity, such as the Bützow (northeastern Germany) tornado event on 5 May 2015 (Maiwald and Schwarz, 2016).

Due to their local-scale nature, convective storms and related phenomena are not entirely and homogeneously recorded over larger areas. For this reason, several studies have tried to establish a connection between convective events and different indirect climate data, so-called proxies. The temporal and spatial variability of convection is then studied using such an appropriately defined proxy. Several papers focusing on ambient conditions favorable for the formation of thunderstorms found a strong relation between several convective parameters and thunderstorm probability, especially for severe storms (e.g., Van Delden, 2001; Brooks et al., 2003; Kunz, 2007; Mohr and Kunz, 2013). More recent studies consider data from radar or satellite as a proxy for hail (e.g., Cecil and Blankenship, 2012; Nisi et al., 2016; Puskeiler et al., 2016; Junghänel et al., 2016). These stud- 
ies found a strong spatial variability of hail probability that is mainly governed by the distance to the ocean and by orographic flow deviations.

In our paper, we used lightning flashes as a proxy for convective activity, since the data are available over several years and the recordings exhibit a high level of homogeneity. Whereas first lightning climatologies were deduced from SYNOP records (e.g., Wakonigg, 1978; Cehak, 1980; Pelz, 1984; Cacciamani et al., 1995), the recently developed electromagnetic sensor networks allow for spatially homogeneous analyses, such as the early study performed by Finke and Hauf (1996) with respect to southern Germany. Several papers focusing on different European regions found various distinct regional and local structures of lightning probability or density (e.g., Schulz et al., 2005; Coquillat et al., 2013; Wapler, 2013; Czernecki et al., 2016). Besides spatial features, the temporal variability on diurnal and annual timescales also shows several peculiarities across the respective investigation areas (e.g., Soriano et al., 2005; Antonescu and Burcea, 2010; Gladich et al., 2011; Santos et al., 2013). In addition, larger-scale investigations of lightning climatology (e.g., Holt et al., 2001; Anderson and Klugmann, 2014; Kotroni and Lagouvardos, 2016) have been performed using very low-frequency networks, implying a lower location accuracy. Satellite-based techniques allowed for developing global lightning climatologies (e.g., Christian et al., 2003; Beirle et al., 2014) but also at the expense of a reduced spatial resolution.

Most of the studies cited above, however, employed relatively short time series. Moreover, they either are restricted to one country or even smaller domains or exclude the analysis of small-scale features due to the lower resolution. Our paper is based on 14 years (2001-2014) of high-resolution, low-frequency (LF) lightning data for the summer half-year (SHY; April-September) covering a large contiguous area consisting of several European countries such as France, Germany, Austria, and Switzerland. This allows for comprehensive and reliable statistical analyses of convective activity under various geographical conditions including the influence of complex orography. In particular, the large sample facilitates the investigation of variability on interannual timescales. Furthermore, many studies employed the quantity lightning density as a measure for convective activity, which suffers from being sensitive to single severe events or outliers. This issue can be resolved by using the dichotomous variable thunderstorm day (TD). Its classical definition as a day with audible thunder or visible lightning at a station (WMO, 2016) has the major drawback of the detection range being limited and highly variable (e.g., Haklander and van Delden, 2003; Bissolli et al., 2007; Novák and Kyznarová, 2011). Based on lightning data, diverse subjective thresholds were used (e.g., Wapler, 2013). We introduce a new, objectified TD definition robust in the case of single severe events and simultaneously allowing for filtering days with sporadic, weak thunderstorms, which are outside the scope of this study.

The objectives of this paper are to develop a comprehensive, high-resolution lightning climatology for large parts of western Europe and to thoroughly investigate the joint characteristics of both spatial and temporal modes of variability. This involves, for instance, discussing regional peculiarities regarding the annual and diurnal cycles of convective activity and addressing the seasonal dependence of diurnal lightning peaks. Moreover, we study several aspects of interannual variability such as spatial correlations of local multiyear TD time series and the impact of the North Atlantic Oscillation (NAO) teleconnection pattern on convective activity.

The paper is structured as follows: in Sect. 2, we briefly describe the different data sets that were used and the methods applied. Section 3 presents our major results and discusses the most relevant drivers and underlying physical mechanisms that plausibly explain the spatiotemporal variability observed. In Sect. 4, we provide a short summary of the key points and draw some conclusions from the results.

\section{Data and methods}

\subsection{Model and observational data}

Convective activity is investigated in a domain comprising the countries of Germany, Austria, Switzerland, the Netherlands, Belgium, Luxembourg, and France (Fig. 1). In addition, data are available for parts of neighboring countries such as the northwesternmost area of Italy, the Spanish part of the Pyrenees, or the Bohemian Forest. The complex terrain of the investigation area, including large parts of the Alps and several low mountain ranges such as the Black Forest and Swabian Jura (s), the Ore Mountains (x), and the Massif Central (e), allows to study lightning activity in the presence of strong altitudinal gradients, glaciated areas, and complex, contorted deep valley systems. In contrast, the North German Plain (v) exhibits only isolated low hills at altitudes barely above sea level. Maritime influence can be expected along the coasts of North Sea and Atlantic Ocean as well as the French part of the Mediterranean.

The investigations cover a 14-year period from 2001 to 2014. Since convective storms in Europe occur most frequently during the warm summer months, we restrict our analysis to SHY from April to September.

\subsubsection{Lightning data}

The spatial and temporal variability of convective activity is examined using data from the ground-based LF lightning detection system BLIDS (BLitz-Informations-Dienst Siemens), which is part of the EUCLID (EUropean Cooperation for LIghtning Detection) network. The detection efficiency has been shown to be $96 \%$ for flashes exhibiting a peak current of at least $2 \mathrm{kA}$, while the location accuracy is $\sim 100 \mathrm{~m}$ 


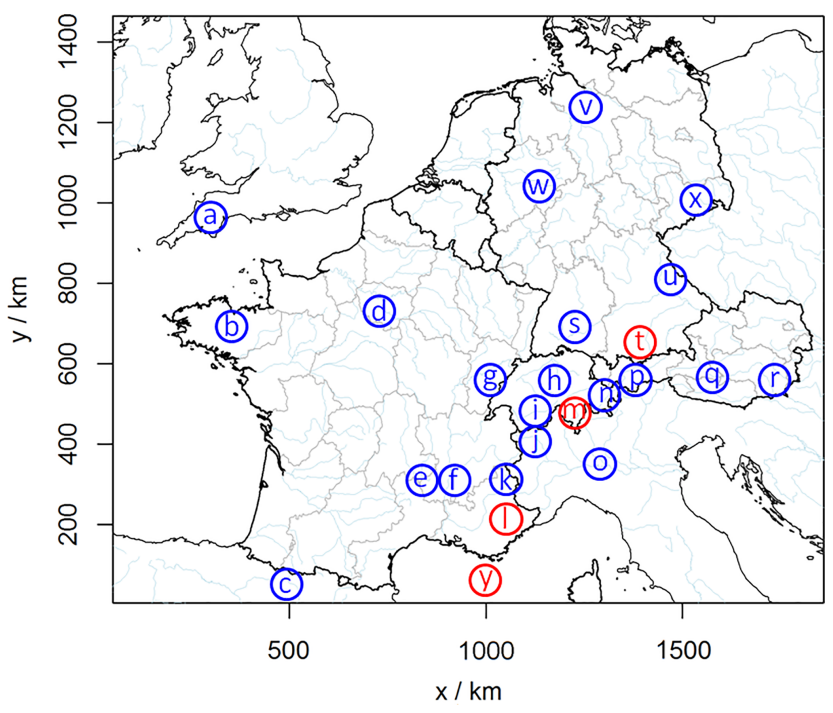

Figure 1. Study domain with regions marked by characters that are referred to in this study: (a) Cornwall, (b) Brittany, (c) southern Pyrenees, (d) Paris Basin, (e) Massif Central, (f) lower Rhône Valley, (g) Jura Mountains, (h) Swiss Prealps, (i) upper Rhône Valley, (j) Aosta Valley, (k) Guisane Valley (north of Briançon), (1) Maritime Alps, (m) Ticino, (n) Grisons, (o) Po Valley, (p) Ötztal Valley in Tyrol, (q) High Tauern, (r) Graz Basin, (s) Black Forest-Swabian Jura, (t) Bavarian Prealps, (u) Bavarian Bohemian Forest, (v) North German Plain, (w) Sauerland, (x) Ore Mountains, and (y) Côte d'Azur. Those regions studied more in detail are highlighted in red.

(Schulz et al., 2016). Information about both polarity and current strength is neglected, and flashes rather than strokes are studied with the grouping procedure performed internally by EUCLID. Since the LF operational range implies a significantly lower detection efficiency of cloud-to-cloud (IC) lightning (Pohjola and Mäkelä, 2013; Schulz et al., 2014), only cloud-to-ground (CG) flashes are taken into account.

\subsubsection{North Atlantic Oscillation index}

Convective conditions and related thunderstorm activity across Europe tend to form larger-scale patterns that exhibit a large annual and interannual variability (e.g., Kunz et al., 2009; Bedka, 2011; Mohr et al., 2015). To examine whether this variability may be partly controlled by major large-scale teleconnection patterns, we considered monthly values of the NAO index. Those data were provided by the US National Oceanic and Atmospheric Administration (NOAA). The calculation of the index values is based on rotated S-mode principal component analysis (PCA; Richman, 1986) applied to monthly mean standardized $500 \mathrm{hPa}$ height anomalies (Barnston and Livezey, 1987; Hurrell and Deser, 2010) obtained from the National Centers for Environmental Prediction - National Center for Atmospheric Research reanalysis (NCEP/NCAR1; Kalnay et al., 1996). The index time series is available from 1950 onwards. However, the relation between thunderstorm activity and the NAO is studied based on a subsample of this time series, which is given by the period from 2001 to 2014 (SHY).

\subsubsection{Reanalysis data}

The output of the global reanalysis model NCEP/NCAR1 is used to examine the dynamical and thermodynamical effects of the NAO phases on convective activity. The NCEP/NCAR1 reanalysis is available for 17 pressure levels and exhibits a spatial resolution of $2.5^{\circ} \times 2.5^{\circ}$. For the analyses performed in this paper, model fields of the wind vector and the equivalent potential temperature at the 300 and $850 \mathrm{hPa}$ pressure levels, respectively, are evaluated. Only data sets at 12:00 UTC are considered since they best mirror the prevailing convective conditions. NCEP/NCAR1 data are available from 1948 onwards. However, the analyses are limited to the time period from 2001 to 2014 (SHY), for which lightning data are available.

\subsection{Statistical methods}

\subsubsection{Binary measure of convective activity: thunderstorm day}

Lightning density usually is defined as the mean daily flash total within a certain grid box. This quantity has been used by several studies to estimate thunderstorm activity (e.g., Schulz et al., 2005; Manoochehrnia et al., 2007; Antonescu and Burcea, 2010; Santos et al., 2012). However, the explanatory value of lightning density suffers from sometimes being dominated by single severe convective storms producing several tens of thousands of flashes. Sporadic severe storm days may result in potentially misleading conclusions about the spatial patterns of convective activity.

This problem can be circumvented by defining a dichotomous variable $\mathrm{TD}$, which takes the value of 1 , if the number of daily flashes within a grid box exceeds a given threshold. Filtering those days with a low number of flashes enables us to focus on days with more intense thunderstorms and neglecting weak convective events such as embedded convection (Fuhrer and Schär, 2005). The optimum threshold in our TD definition is determined by an objective method. For this, the domain is subdivided into a grid consisting of $10 \times 10 \mathrm{~km}^{2}$ equidistant cells. Excluding all days without any flash in a respective grid cell, the empirical probability density distribution is computed for each cell separately. Averaging over the entire domain yields the distribution shown in Fig. 2. The threshold is determined by choosing the integer value just above the interval of strongest curvature, yielding a lower threshold of five flashes per day within a grid cell. This threshold excludes the large number of weak events but simultaneously yields sufficiently large sample sizes. Therefore, for all subsequent investigations a day (from 00:00 to 


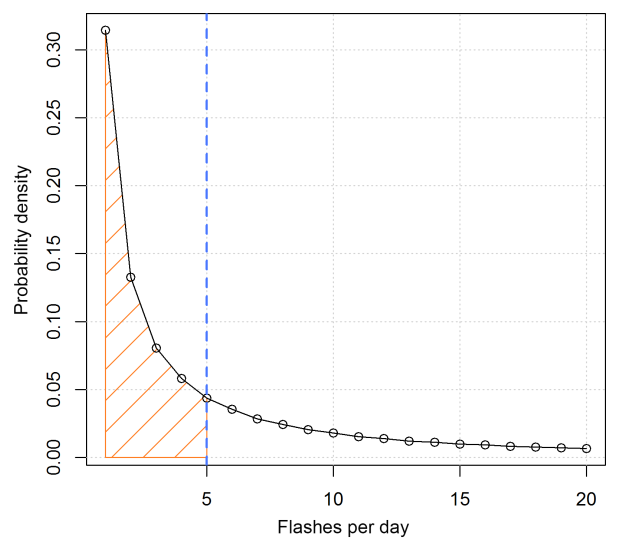

Figure 2. Empirical probability density distribution of daily flash numbers averaged over all grid cells within the entire investigation area during the period 2001 to 2014. Indicated are the separator between the regimes' TD (yes/no; vertical dashed line) and the probability for a day with lightning that is not classified as TD (orange hatched area).

00:00 LT on the next day) is classified as TD if at least five flashes were registered within a $10 \times 10 \mathrm{~km}^{2}$ grid cell.

\subsubsection{Probability density function}

To provide a rough overview of the diurnal lightning incidence in different subregions, $24 \mathrm{~h}$ flash totals are fitted to a theoretical probability density function. For this purpose, it is reasonable to consider all days with lightning events instead of setting a certain threshold. Due to high skewness expected in connection with a large number of days with only a small number of flashes, the two-parameter gamma distribution is an appropriate choice:

$f(x)=\frac{\left(\frac{x}{k}\right)^{\alpha-1} \exp \left(-\frac{x}{k}\right)}{k \Gamma(\alpha)}$,

where $\Gamma$ is the gamma function and $\alpha$ and $k$ are shape and scale parameter, respectively (Wilks, 1995). The fitting procedure is performed using the method of $\mathrm{L}$ moments, which is a more robust alternative to the conventional method of moments (Hosking, 1990). Goodness of fit is assessed by analyzing a quantile-quantile plot (Wilks, 1995).

\subsubsection{Dispersion and correlation of annual TD numbers}

To determine the sample dispersion of the annual TD time series within a specific grid cell, we considered the coefficient of variation $\hat{v}$, which is defined by the sample standard deviation $\hat{\sigma}$ normalized by the sample mean $\hat{\mu}$, and thus independent of the latter quantity (Kohn, 2006): $\hat{v}=\frac{\hat{\sigma}}{\hat{\mu}}$.

Apparently, $\hat{v}$ exhibits a singularity for $\hat{\mu} \rightarrow 0$, which must be kept in mind when analyzing the dispersion in areas with weak convective activity.

To identify and further examine related patterns of specific convective activity, annual TD time series at selected locations were correlated with those of all grid points in the investigation area. We used the Spearman rank correlation coefficient $r_{\mathrm{s}}$ since it is independent of the underlying probability density function and more robust against outliers compared to the widely used Pearson product-moment coefficient (Wilks, 1995). In this way, correlation maps with respect to selected reference grid cells were obtained. For the sake of better comparability, the underlying time series were smoothed by a moving window before. We tested the results for statistical significance by applying the univariate bootstrap method, which should be preferred to bivariate bootstrapping especially for small sample sizes (Lee and Rodgers, 1998). If $n$ represents the length of the sample time series, the univariate algorithm implies randomly drawing $n$ times with replacement from each of the two samples separately. This procedure is repeated 1000 times, leading to the null distribution of the correlation coefficient. In the sense of a two-sided test, the null hypothesis $H_{0}$ is rejected if the observed $r_{\mathrm{s}}$ is greater than the $97.5 \%$ quantile or less than the $2.5 \%$ quantile of the null distribution $(\alpha=0.05)$.

\subsubsection{NAO and convective activity}

We investigated the influence of the NAO on the mean spatial distribution of convective activity in Europe by assessing the deviations of TD frequency from climatology during strongly positive $(\mathrm{NAO}>1)$ and negative $(\mathrm{NAO}<-1)$ phases. For this purpose, the variable $D$ measuring the influence of the NAO index on convective activity was defined as

$D_{ \pm}=\frac{\operatorname{rf}\{\mathrm{TD}=1 \mid \mathrm{NAO} \gtrless \pm 1\}-\operatorname{rf}\{\mathrm{TD}=1\}}{\operatorname{rf}\{\mathrm{TD}=1\}}$,

with $\operatorname{rf}\{a \mid b\}$ denoting the mean relative frequency of event $a$ given event $b$. Thus, mean relative frequencies obtained by averaging over the monthly TD frequency values were compared between the respective NAO phases and the climatology. Since the NAO anomaly patterns do not exhibit strong spatial shifts during SHY, we decided not to differentiate between the individual months. The variable $D$ was calculated for each grid cell separately. A value of $D=1$ means that thunderstorm days are twice as frequent during the respective NAO phases (positive or negative) as compared to the total sample. We assessed significance by means of a two-sided bootstrap test $(\alpha \in\{0.05,0.10\})$ regarding the test statistic $D_{ \pm}$. Here, the null hypothesis $H_{0}$ states that an observed relation between NAO and lightning activity within a grid box is simply due to chance. 


\section{Results}

In the following, spatial and temporal patterns of TD numbers across the investigation area are discussed. More detailed analyses are presented for four example subregions representative of specific characteristics of convective activity: Ticino ( $m$ in Fig. 1), Côte d'Azur (y), Maritime Alps (l), and Bavarian Prealps (t).

\subsection{Spatial distribution of convective activity}

The mean annual number of TDs presented in Fig. 3 shows a very large spatial variability. On the large scale, the distribution is dominated by a distinct northwest-to-southeast gradient, which is mainly caused by the distance to the Atlantic substantially affecting the general climate. While fewer than two TDs occur on average over Brittany (indicated by $b$ in Fig. 1) and Cornwall (a), more than 20 days are found in the vicinity of the Alps. Superimposed on this overall trend are several substructures on the regional scale such as the local maximum downstream of the Black Forest (s) and the minimum in the upper Rhône Valley (i). These substructures are mainly related to flow deviations, thermally driven wind systems, and the local potential for moisture flux convergence in the presence of orography.

The three primary maxima all extend along the southern Alpine range. One of them stretches across the region between the Swiss canton of Ticino (m) and the Italian city of Turin in the southwest (up to 21 TDs). Similar values are reached in southern Austria, namely along a bow-shaped area between the eastern edge of the High Tauern (q) and the foothills northeast of Graz (r). In addition, high values (up to 13 TDs) are observed widespread across the Austrian Eastern Alps. The third principal maximum (up to 16 days) is located north of Nice over the Maritime Alps (l), extending, albeit weakened, northward to Lake Geneva and along the Swiss Prealps (h).

Ticino has already been identified in previous studies as one of Europe's core areas regarding thunderstorm activity (Van Delden, 2001; Schulz and Diendorfer, 2002; Nisi et al., 2016). The distinct maximum can be linked to increased instability due to the abundance of low-level moisture. Instability is even further increased when cold air masses advected from the northwest and blocked by the Alps at lower levels reach Ticino aloft only (Costa et al., 2001). Convection triggering mechanisms are provided by orographically induced flow deviations, outflows from mature convective cells, and catabatic-anabatic wind systems leading to low-level convergence zones (Gladich et al., 2011; Nisi et al., 2016). Over southern Austria, the high number of TDs already found by other authors (e.g., Wakonigg, 1978; Schulz et al., 2005; Punge and Kunz, 2016) can be plausibly explained by advection of unstable air from the southeast and subsequent lifting at the nearby foothills. Regarding the Maritime Alps (l), their close proximity to the Mediterranean allows for very moist

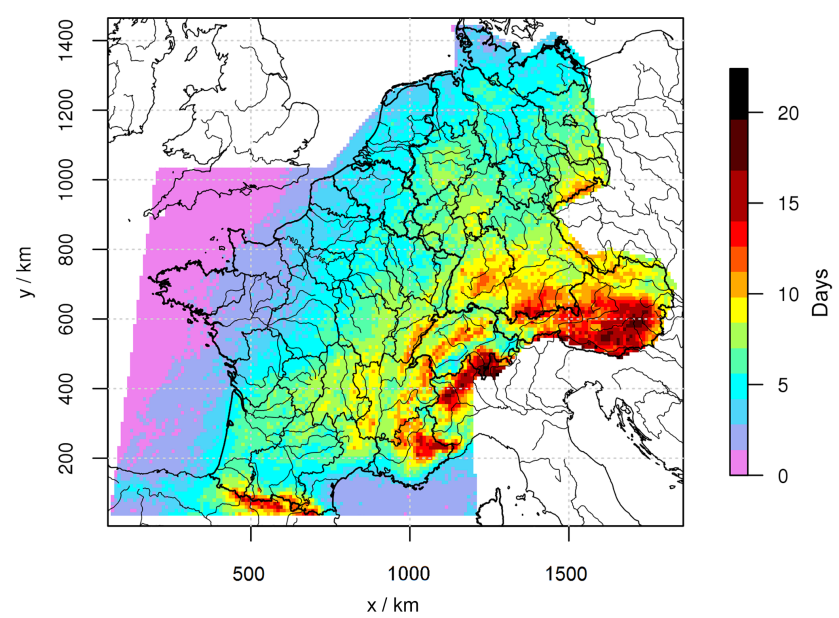

Figure 3. Mean annual number of thunderstorm days during the summer half-years 2001-2014.

and warm maritime air being lifted over the complex topography.

Besides the TD maxima connected to the Alps, elevated values are also found in the vicinity of low mountain ranges or hilly terrain. In Germany, the most prominent maxima are located over the Bavarian Prealps ( $t ; \sim 15$ TDs) and between Black Forest and Swabian Jura (s; $\sim 12$ TDs). Secondary maxima can be observed over the Ore mountains (x), the Bavarian Bohemian Forest (u), and, unlike previously stated (Finke and Hauf, 1996), only over some parts of the hill terrain to the west, for example the Sauerland (w; 9-11 TDs). A further remarkable feature is the meridional streak of increased values along the German-Polish border ( $\sim 9$ TDs). In France, the strongest extra-Alpine lightning activity is observed over the Pyrenees with highest values registered on Spanish territory in the south (c, $\sim 14$ TDs). Other maxima are located over Massif Central (e) and the Jura Mountains (g). Remarkably, a broad streak of higher frequencies also ranges from the Bay of Biscay to the northeast.

Regarding ambient conditions, the increased TD values in southern Germany can be attributed to a pronounced northto-south gradient in thermal stability or convective energy (Brooks et al., 2003; Mohr and Kunz, 2013). Specifically, the maximum between Black Forest and Swabian Jura has been explained in previous studies with flux convergences and gravity waves forming downstream of the Black Forest in conjunction with moist air advection from the upper Rhine Valley (Kunz and Puskeiler, 2010; Puskeiler et al., 2016). Relatively high values along the German-Polish border peaking in the Ore Mountains can be interpreted as an extension of the High Tatras lightning maximum found by Czernecki et al. (2016). Our results obtained for France largely conform with the findings of others, for example Lassègues et al. (2003). Elevated mixed layers originating from the Spanish plateau, known as the Spanish Plume (Mor- 
ris, 1986), frequently lead to the formation of thunderstorm tracks observed between the Bay of Biscay and Massif Central (Van Delden, 1998). Thunderstorm development over the Pyrenees is favored by moist Mediterranean air masses being advected along the Ebro Valley in Spain (see Soriano et al., 2005; Santos et al., 2013).

Conversely, pronounced minima with only one ore two TDs are found over Brittany (b) and Cornwall (a). Other areas with a low TD number include the upper Rhône Valley northwest of Ticino (i), large parts of the canton of Grisons, Switzerland (n), and the Ötztal Valley in Tyrol, Austria (p). In addition, two narrowly confined minima can be detected along the French-Italian border. In the upper Aosta Valley (j), only 7 TDs are observed as opposed to the 13 TDs just below the marked bend. Even lower values are present in the Guisane Valley north of Briançon (k) in France.

Convective activity does not reach its minimum over glaciated mountain ranges as proposed by earlier studies (e.g., Manoochehrnia et al., 2007) but along the neighboring deep valleys. Due to shadowing effects, the evolution of moisture flux convergences is strongly impeded there. In contrast, the presence of snow and ice cover in summit regions reduces thunderstorm frequency to a much lesser extent, as can be seen for example by the comparatively high number of TDs in the partially glaciated High Tauern in Austria (q). Low TD numbers over Brittany and, likewise, along the Baltic Sea coast can be explained by the stabilizing effect of the cool sea water during summer months. Note that the extension of the Breton landmass seemingly is not sufficiently large in order to allow for a local increase in convective activity due to solar heating. In spite of higher temperatures, the Mediterranean also stabilizes the maritime boundary layer, leading to a reduction in thunderstorm activity along the Côte d'Azur (Anderson and Klugmann, 2014). It must be stressed that the Mediterranean simultaneously serves as an important source of moisture for convective cell formation over the neighboring Maritime Alps as previously mentioned.

Considering lightning density instead of TDs, spatial variability is characterized by a largely similar large-scale pattern of minima and maxima (not shown). Moreover, it can be shown that the annual TD number at a specific grid cell is highly correlated with the annual lightning density at this grid cell. Pronounced differences between TD number and lightning density on the local scale, however, occur where TDs go along with lower or higher flash numbers compared to the mean. This effect can be studied comparing gamma distributions fitted to diurnal flash numbers among six exemplary subregions (Table 1). Recall that increasing shape and scale parameters, $\alpha$ and $k$, result in less skewness and stretching towards higher values, respectively (see Eq. 1). Therefore, large values of both $\alpha$ and $k$ imply a relatively high probability of those TDs exhibiting a high number of lightning flashes. $k$ generally has the same dimension as the quantity studied and can therefore be looked upon as some
Table 1. Gamma distribution shape $(\alpha)$ and scale $(k)$ parameter values with respect to daily flash numbers in various regions. For better comparability, flash numbers have been spatially averaged over the single grid cell values.

\begin{tabular}{lcc}
\hline Region & $\alpha$ & $k$ \\
\hline Ticino & 0.086 & 33.0 \\
Maritime Alps & 0.092 & 25.6 \\
Bavarian Prealps & 0.084 & 23.5 \\
Côte d'Azur & 0.050 & 17.0 \\
Pyrenees & 0.113 & 10.5 \\
Brittany & 0.035 & 5.2 \\
\hline
\end{tabular}

sort of characteristic daily flash number describing the respective distribution. Conversely, $\alpha$ is dimensionless and a value of $\alpha<1$ implies that the distribution approaches infinity in the limit of zero. As expected, high flash numbers are emphasized in the distributions belonging to several hot spots of TD occurrence, such as Ticino $(k=33.0)$, Maritime Alps $(k=25.6)$, and southern Bavaria $(k=23.5)$. Conversely, the Pyrenees, albeit representing a prominent maximum with respect to TDs as well, are characterized by a substantially lower scale parameter $(k=10.5)$. Regarding the locations of TD minima, the fitting result shows that the Brittany expectedly exhibits very low lightning incidence $(k=5.2)$, as opposed to a fairly high scale parameter at Côte d'Azur $(k=17.0)$. The anomalies of $k$ observed both for the Pyrenees and Côte d'Azur are only partially compensated for by the shape parameter. Thus, the extrema visible in Fig. 3 can be grouped according to the average lightning incidence per TD.

\subsection{Temporal variability on diurnal and seasonal scales}

Besides the spatial variability discussed in the previous paragraph, convective activity exhibits a strong temporal variability on diurnal, seasonal, and interannual timescales. The following section investigates the two former modes of variation.

\subsubsection{Joint annual-diurnal cycles of lightning frequency}

In addition to the large spatial variability in TDs as discussed in the previous section, the diurnal cycle of lightning frequency differs considerably across the investigation area. In the example regions, the global maxima occurring in the afternoon or evening over the Maritime Alps, Ticino, and Bavarian Prealps are distinctly shifted against each other by several hours (Fig. 4). While the maximum in the former region is registered around 14:00 LT, it occurs $4 \mathrm{~h}$ later at 18:00 LT in Ticino and at 20:00 LT in the Bavarian Prealps. Furthermore, while in Ticino lightning has an elevated frequency during nighttime, it is substantially reduced over 


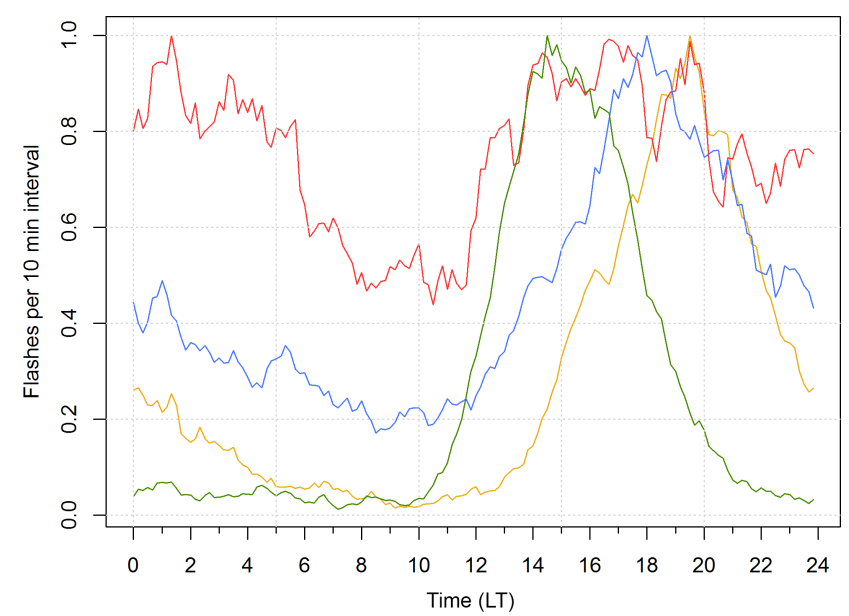

Figure 4. Average diurnal cycle of $10 \mathrm{~min}$ flash numbers, normalized by the respective maximum, for the four regions: Ticino (blue), Côte d'Azur (red), Maritime Alps (green), and Bavarian Prealps (yellow); time has been converted to local time (LT).

the Maritime Alps, especially between 22:00 and 10:00 LT. Contrarily, high levels of lightning persist also throughout the night over the Côte d'Azur, yielding two broad peaks between 00:00 and 06:00 LT and between 13:00 and 20:00 LT.

Plotting mean annual cycles of TD frequency for the four example subregions (Fig. 5) likewise reveals distinct spatial features. Predominantly, convective activity exhibits a broad summer maximum accompanied by a strong increase and decrease in spring and autumn, respectively, whereas it is characterized by a sharp autumn maximum at Côte d'Azur. However, even those regimes with frequent summer lightning differ significantly from one another; for example TD frequency increases much later in Ticino than in southern Bavaria or the Maritime Alps, where autumn decrease in turn is delayed.

To consider both daily and annual cycle, jointly, we used a kind of Hovmöller diagram for the four example regions showing the normalized lightning frequency as a function of the two temporal modes (Fig. 6). To better highlight the most important temporal patterns, two-dimensional smoothing of the data was performed by employing 10-day and $100 \mathrm{~min}$ running means, respectively. As can be seen, most diurnal cycles vary substantially throughout the year with large differences found also among neighboring regions such as Maritime Alps and Ticino. The former distribution (Fig. 6a) exhibits a symmetric diurnal cycle with almost vanishing nighttime activity and a maximum around 15:00 LT remaining approximately constant from the middle of June until the beginning of August. In Ticino, contrarily, nighttime and morning thunderstorms are quite common (Fig. 6b), but not before the end of June. The afternoon maximum is shifted into the early evening (18:00 LT) with the season of highest values distinctly shortened compared to the Maritime Alps. Along the Bavarian Prealps, the diurnal cycle has some similarities with that of the Maritime Alps, but it is clearly displaced to-

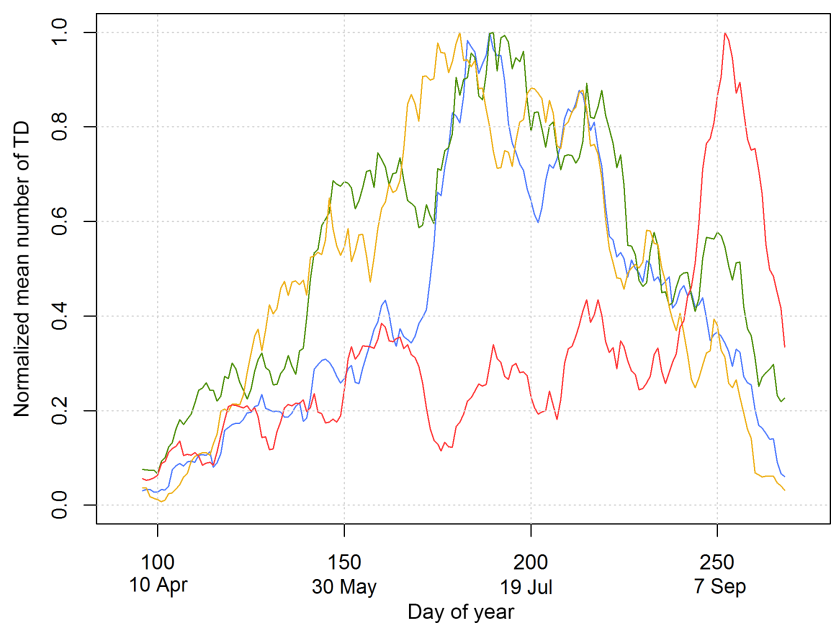

Figure 5. Mean relative TD frequency as 10-day moving average within intervals centered at the indicated days of year for the regions Ticino (blue), Côte d'Azur (red), Maritime Alps (green), and Bavarian Prealps (yellow). Each curve has been normalized by its respective maximum.

wards later hours and consequently extends until after midnight (Fig. 6c). Both in Ticino and the Bavarian Prealps, the late summer drop in evening lightning frequencies (see Fig. 5) does not imply cessation of nighttime activity. In contrast, lightning frequencies behave completely differently at Côte d'Azur, where a weak afternoon maximum is visible during summer months in addition to sporadic nighttime activity, before the diurnal cycle changes entirely in September with a pronounced maximum extending from the afternoon all over the night (Fig. 6d).

Several other studies (e.g., Schulz et al., 2005; Novák and Kyznarová, 2011; Wapler, 2013) that focused on parts of our investigation area have already identified the afternoon peaks in lightning frequency as a prominent feature. Our results, however, suggest that lightning regimes behave more diversely in regard to the time of the maxima and, in particular, the seasonal variation of diurnal cycles. The large discrepancies between the Maritime Alps and Ticino lightning regimes, despite both being particularly steered by orographic lifting of Mediterranean air masses, can be plausibly explained by a differing level of convective organization. In the former domain, thunderstorms preferably are initiated as single cells at the mountain slopes, which dissipate quickly in the evening hours, when radiative cooling sets in. In contrast, nighttime thunderstorms in the latter region can be attributed to convergence zones due to complex orographic features and outflows from mature cells (Gladich et al., 2011; Nisi et al., 2016) frequently leading to long-lived mesoscale convective systems (Morel and Senesi, 2002). Organized convection has been shown to be also important in the Bavarian Prealps by Van Delden (2001). This type of convection causes the time shift of maximum lightning frequency rela- 

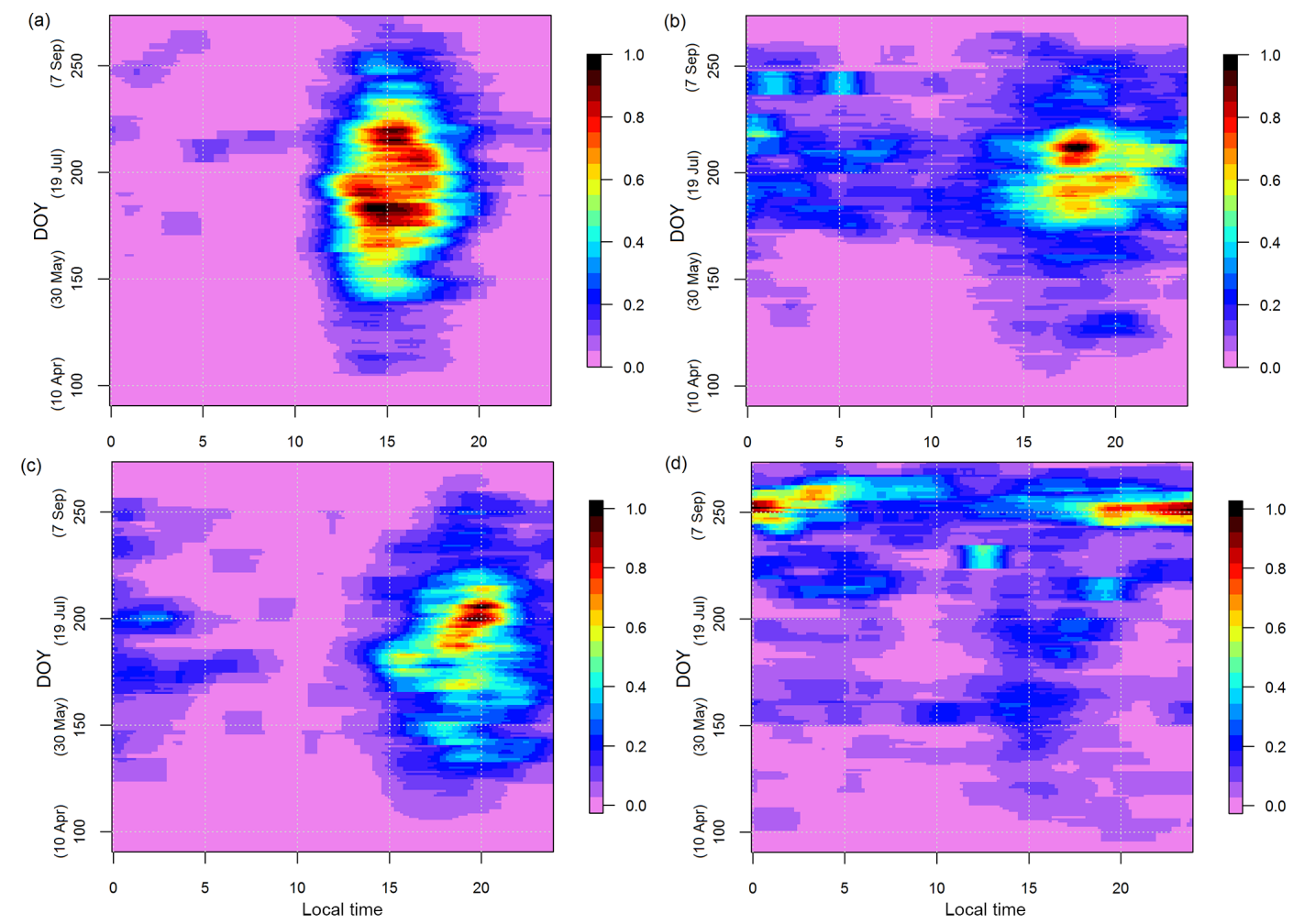

Figure 6. Average flash number as a function of local time (10 min intervals) and day of year, normalized by the maximum values for the regions Maritime Alps (a), Ticino (b), Bavarian Prealps (c), and Côte d'Azur (d). Data have been smoothed applying a 10-day and 100 min running mean.

tive to the Maritime Alps. The seasonally dependent influence of the Mediterranean on stability accounts for further noticeable features described above, such as the jump of Ticino lightning frequency at all times of the day found for the end of June and the distinct change in the Côte d'Azur diurnal cycle taking place in early autumn (see Sect. 3.2.2). Frequent nighttime lightning in September over the western Mediterranean has also been found by Santos et al. (2013). In the coastal zone, land breezes might additionally favor thunderstorm activity during night.

\subsubsection{Monthly patterns of thunderstorm days}

The findings obtained in the previous subsection suggest analyzing the regional peculiarities of seasonality more in detail. For this purpose, we calculated the mean spatial distribution of TD numbers for each month separately (Fig. 7). Generally, these maps confirm the dominance of a single summertime maximum in most areas caused by the seasonality of insolation and low-level temperature. However, several pronounced local differences are visible as well. In April, convective activity is already slightly increased in those regions, where the overall primary maxima occur. Over the High Alps, TDs do not occur at all. In May and June, maximum values are observed in southern Austria (3.5 and 5 TDs, respectively), with the area of peak activity shifted southwest- ward. At this time, TD frequency in Ticino is markedly lower than in Austria before the Ticino maximum becomes dominant from July onwards (up to 7 TDs). Note the clear delay of springtime increase in the latter area compared to the Bavarian Prealps (see Fig. 5). In August, lightning activity decreases nearly everywhere except for the Côte d'Azur area. There and in the adjacent lower Rhône Valley, convection even becomes more frequent in September (up to $1.8 \mathrm{TDs}$ ). Although TDs have turned quite rare in most regions by then, the Ticino and Pyrenees maxima are still present ( 2 and 2.5 TDs, respectively).

In Graz Basin, low-level moisture is able to accumulate much earlier than in the Alpine areas located farther to the west. There, later snow melt additionally prevents the slopes from being heated by the sun in spring (Wakonigg, 1978; Bertram, 2000), which particularly affects the summit regions. Both factors lead to the southwestward shift of lightning activity in Austria culminating in very high TD numbers at the western edge of the High Tauern in July, which might be caused by moisture flux convergence at the junction of the two major Drau and Puster valleys. Whereas stabilization by the cool Mediterranean damps the Ticino maximum until June, the favorable local orographic features (see Sect. 3.1) lead to the extremely intense activity observed in July. This southwestward relocation of the peak convective 

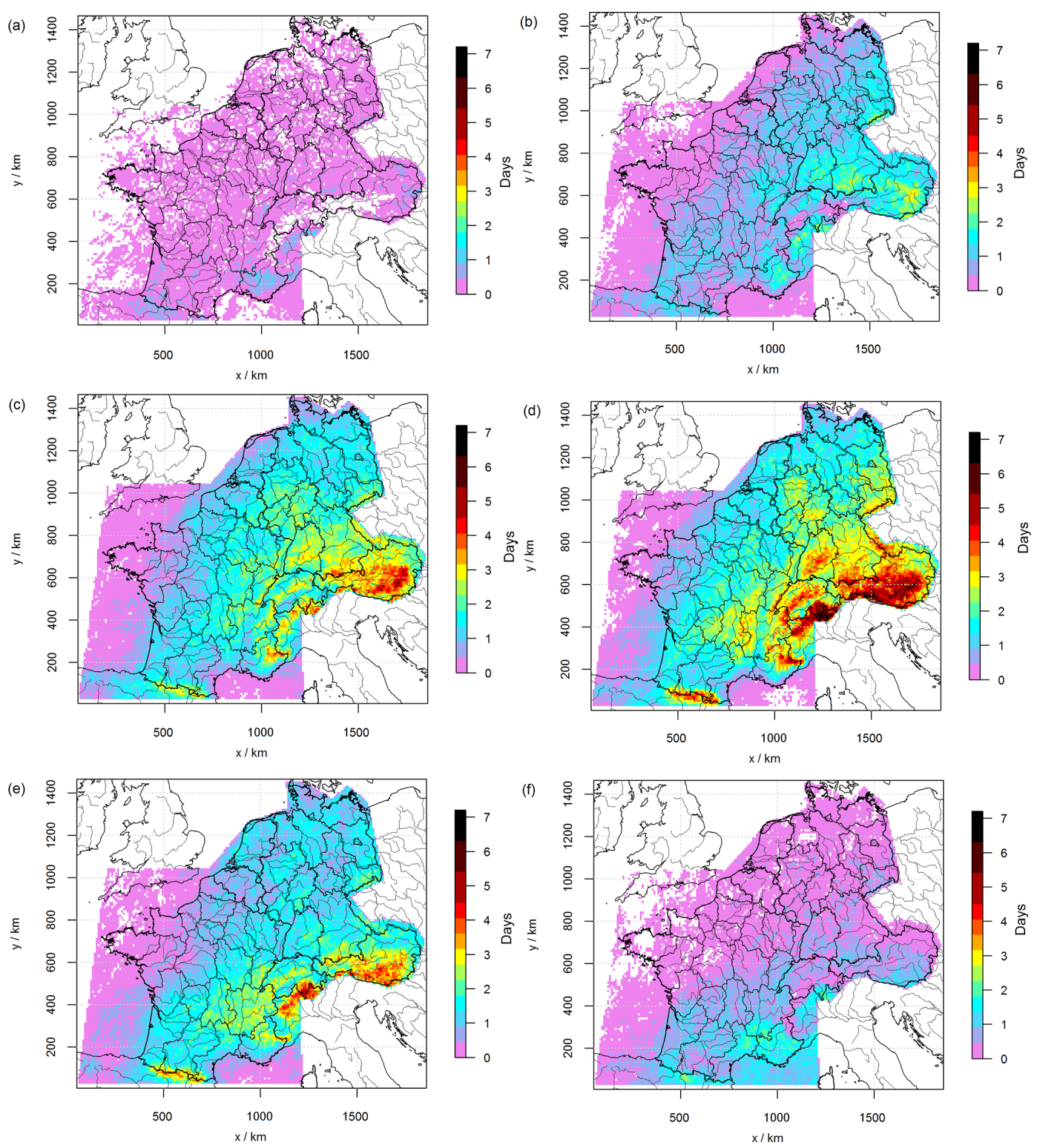

Figure 7. Mean number of thunderstorm days during the summer half-years 2001-2014 in April (a), May (b), June (c), July (d), August (e), and September (f).

region agrees with the results of an earlier study concerning MCS frequency (Morel and Senesi, 2002). In September, lightning events have become rather scarce because of a decrease of mean potential instability in connection with solar insolation weakening. Simultaneously, the Mediterranean meanwhile has warmed considerably relative to the air, favoring thunderstorm formation in the adjacent areas and leading to the striking rearrangement of the spatial pattern of convective activity observed. Anderson and Klugmann (2014) showed that this effect even strengthens in October, for which we have no data.

\subsubsection{Duration of annual lightning period}

The large differences in seasonality suggest investigating the duration of annual lightning period separately for each grid cell. For this, we determined the average values of those days of year when the first and last TD occur (Fig. 8).

Both patterns of first and last TD occurrence are connected to the mean spatial distribution of TDs (Fig. 3) in the sense that a high/low local TD number usually implies a longer/shorter lightning period. Examples for this relation include the pronounced northwest-to-southeast gradient and the discrepancy between the Ticino-Turin region (end of April until beginning of September) and the nearby upper 

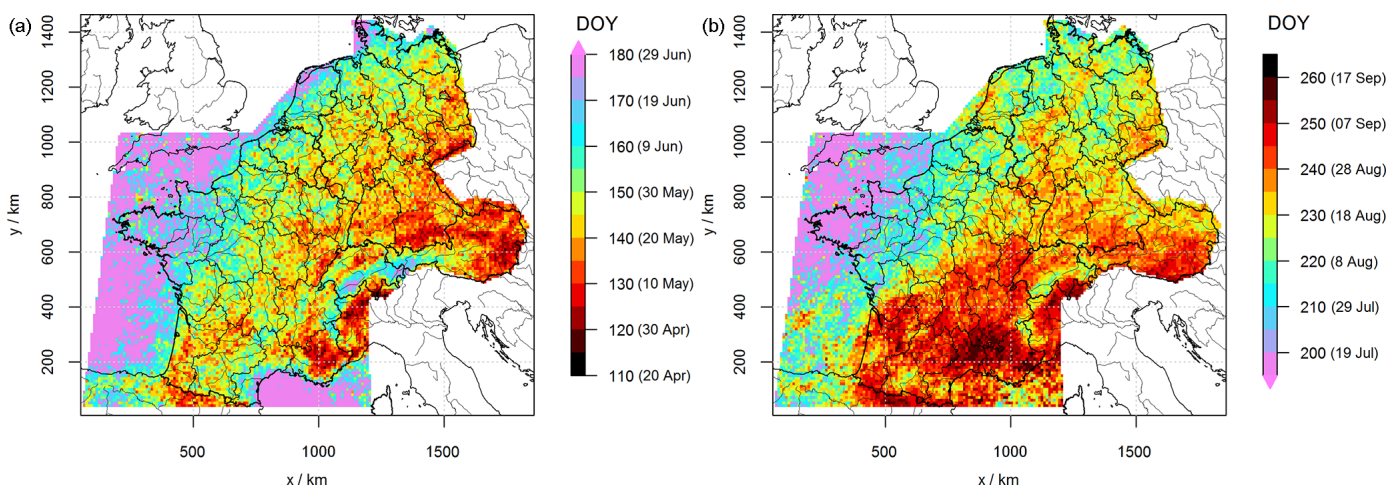

Figure 8. Mean day of year when the first (a) and last (b) thunderstorm days occur.

Rhône Valley (end of June until first half of August). Apparently, locations favoring the development of convective cells are in many cases characterized by a long persistency of these conditions as well. However, lightning regimes behave in a more complex way in several regions. For instance, orographic features are attenuated regarding the distribution of the last TD recording (e.g., Maritime Alps, upper Rhône Valley, and northern Alpine range), which, in addition, bears much less resemblance to the mean pattern of convective activity than the distribution of the first TD. Instead, that pattern is characterized by a broad area in southern France, where TDs occur widely spread late in the year, particularly in the surroundings of the lower Rhône Valley near to the Mediterranean coast (middle of September). Furthermore, the convective period over the Mediterranean itself starts late but lasts quite long with the last TD observed in the first half of September.

Three steering factors already mentioned in Sect. 3.2.2 trigger these pronounced differences: persistent snow cover, lack of low-level moisture, and the annual cycle of sea surface temperature (SST) of the Mediterranean. Since the two former conditions strongly impede thunderstorm formation in the High Alps and the adjacent deep valleys until late spring (see Fig. 7a and b), convective season is delayed in those regions compared to their forelands, leading to the strong gradients observed in the first TD distribution (Fig. 8, left panel). The role of SST, already identified as one of the main drivers of annual TD cycle (see Figs. 5 and 7), is reflected by the very late cessation dates occurring north of the French coast. Note in particular that the reduced thermal stability connected to high SST allows for late last TDs everywhere in that region, independent of prevailing orographic structures.

\subsection{Interannual variability}

Even though a period of 14 years, where lightning observations are available, is far below a climatological time span (e.g., 30 years), it is sufficient to study interannual variability in addition to the diurnal and seasonal cycles discussed above. However, due to the relatively short time series, the main focus is the spatial scales of convective activity and the potential relation to teleconnections.

\subsubsection{Variability of annual TD numbers}

Annual lightning totals vary substantially during the time period considered. In the year 2006, for example, a total of 3.6 million lightning flashes were recorded, whereas convective activity was rather low, with approximately 2.1 million flashes, in 2010 and 2012. Simultaneously, complex spatial differences regarding interannual variability are present. Although there are some years with increased or reduced TDs nearly everywhere, such as in 2006 or 2010, respectively (Fig. 9a and b), frequencies usually do not behave spatially consistently. One example is the pattern observed for the year 2001, when the Ticino-Turin maximum already discussed above has developed well in contrast to low values in southern Austria and over the Pyrenees. Other distinct local maxima such as those of the Paris Basin (d in Fig. 1) or around Hamburg (v) are not present in the 14-year mean (see Fig. 3). In 2013, contrariwise, the Pyrenees and Maritime Alps exhibit increased convective activity in contrast to Ticino and southern Austria.

The large annual and interannual variability of lightning frequency can be attributed - at least partly - to prevailing upper-tropospheric flow patterns favoring or preventing thunderstorm development. In addition, as shown by Piper et al. (2016), days with large-scale weather types favorable for convection frequently form clusters of several days; i.e., the incidence of such weather types implies a considerable probability of a longer-lasting convective situation. This persistent behaviour amplifies the number of the corresponding favorable flow patterns in those years, when they frequently set in, and hence the interannual variability of convective activity.

Another aspect of interannual convective variability is the dispersion of TD numbers, which can be assessed for each grid cell using the coefficient of variation (CV; Sect. 2.2.3). Notably, large parts of the investigation area exhibit a fairly 

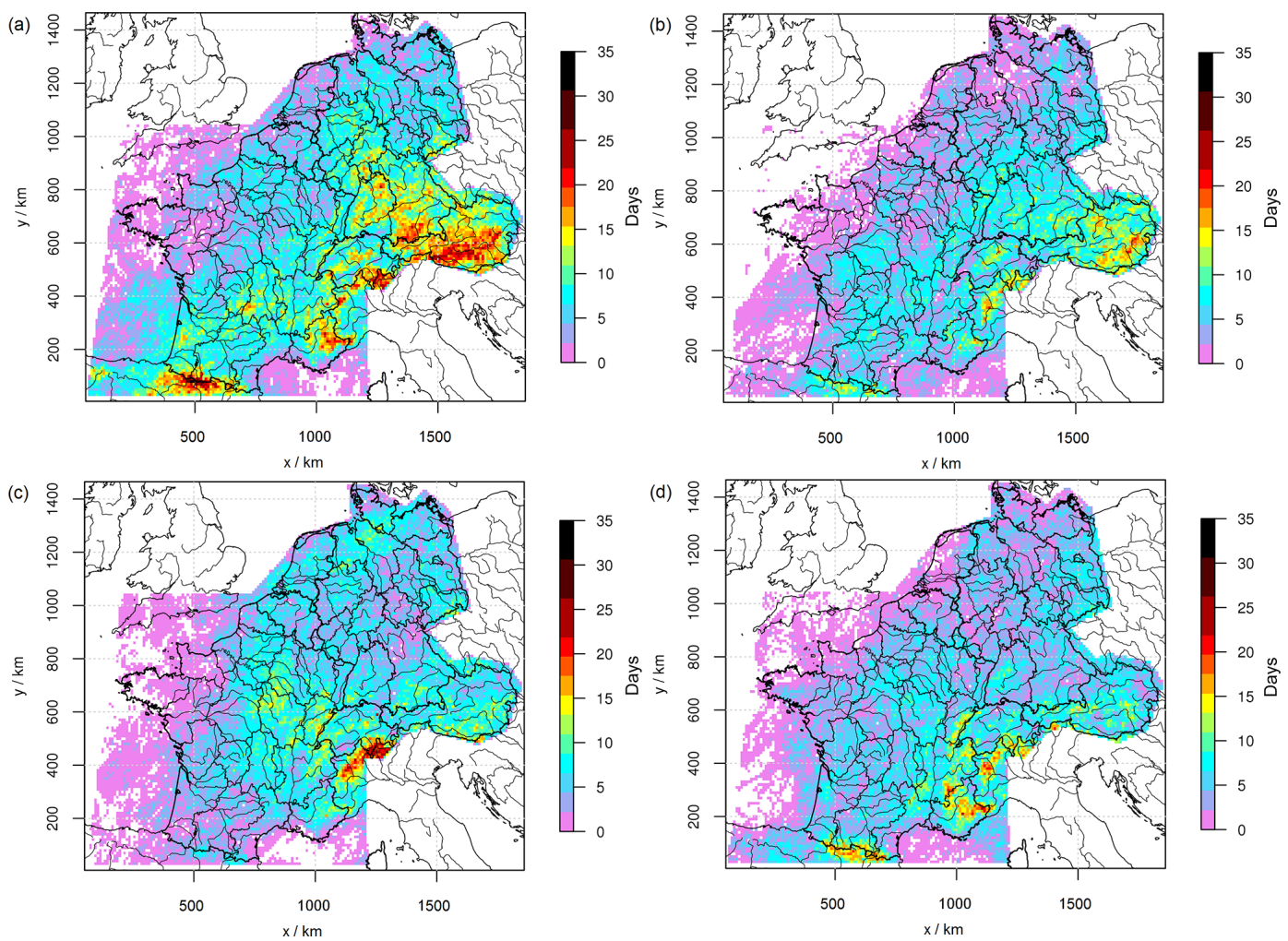

Figure 9. Annual number of thunderstorm days during the summer half-years 2006 (a), 2010 (b), 2001 (c), and 2013 (d).

homogeneous CV pattern with values around 0.4 (Fig. 10), taking into account a considerable background noise of \pm 0.1 . Thus, no significant spatial fluctuations of dispersion are visible here in spite of the spatial peculiarities regarding yearto-year variability discussed above. Nonetheless, CV values are higher in areas where mean TD numbers are particularly low, and vice versa. For example, higher values at several grid points are obtained for regions with infrequent lightning such as northern Germany. Note, however, that higher values and larger gradients of CV may be caused by small integer numbers, where an increase in TD frequency by only 1 day in a specific year yields a stronger increase when the number of TDs is low. This effect culminates over the Atlantic with values up to 3.3 , where $\mathrm{CV}$ approaches its singularity.

\subsubsection{Spatial correlations}

According to the findings described in the previous subsection, interannual variability is only partially coupled among different regions. Comparing correlation maps for four different reference points (Fig. 11) shows that the peripheries, inside of which the time series tend to cohere, largely vary in terms of area and shape. The grid cell located between the Black Forest and Swabian Jura (Fig. 11a) exhibits significant correlations with a vast region extending from the French Alsace to the easternmost parts of Austria. Conversely, the area of correlated grid cells strongly decreases when the ref-

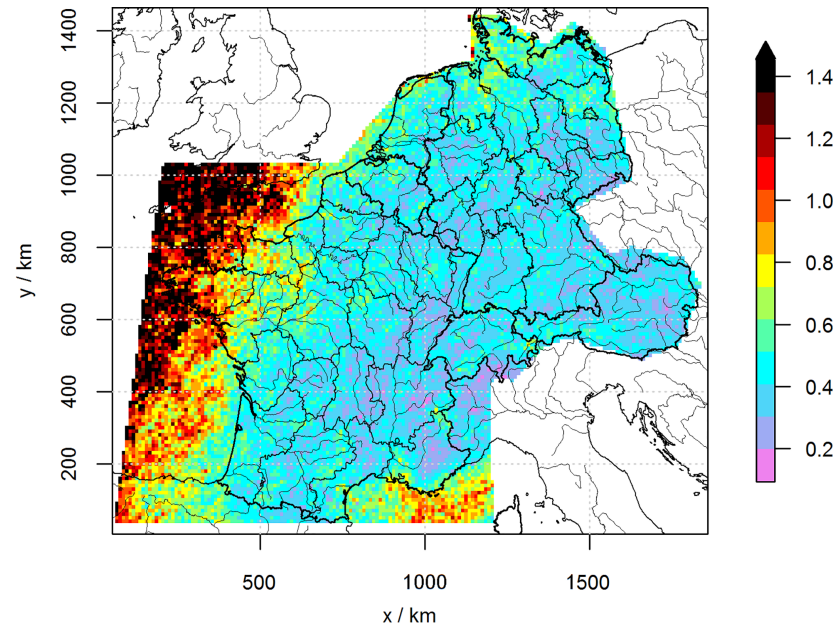

Figure 10. Dispersion of the annual number of thunderstorm days measured by the coefficient of variation.

erence cell is set to a location northeast of the Ore Mountains (Fig. 11b). Here, significant correlations lie inside of a narrow band ranging from the western edge of the Ore Mountains along the Czech and Polish border all the way northward to the Baltic Sea coast. When looking at correlations with respect to the southern Pyrenees (Fig. 11c), we find high values not only along the main axis of the Pyrenees 

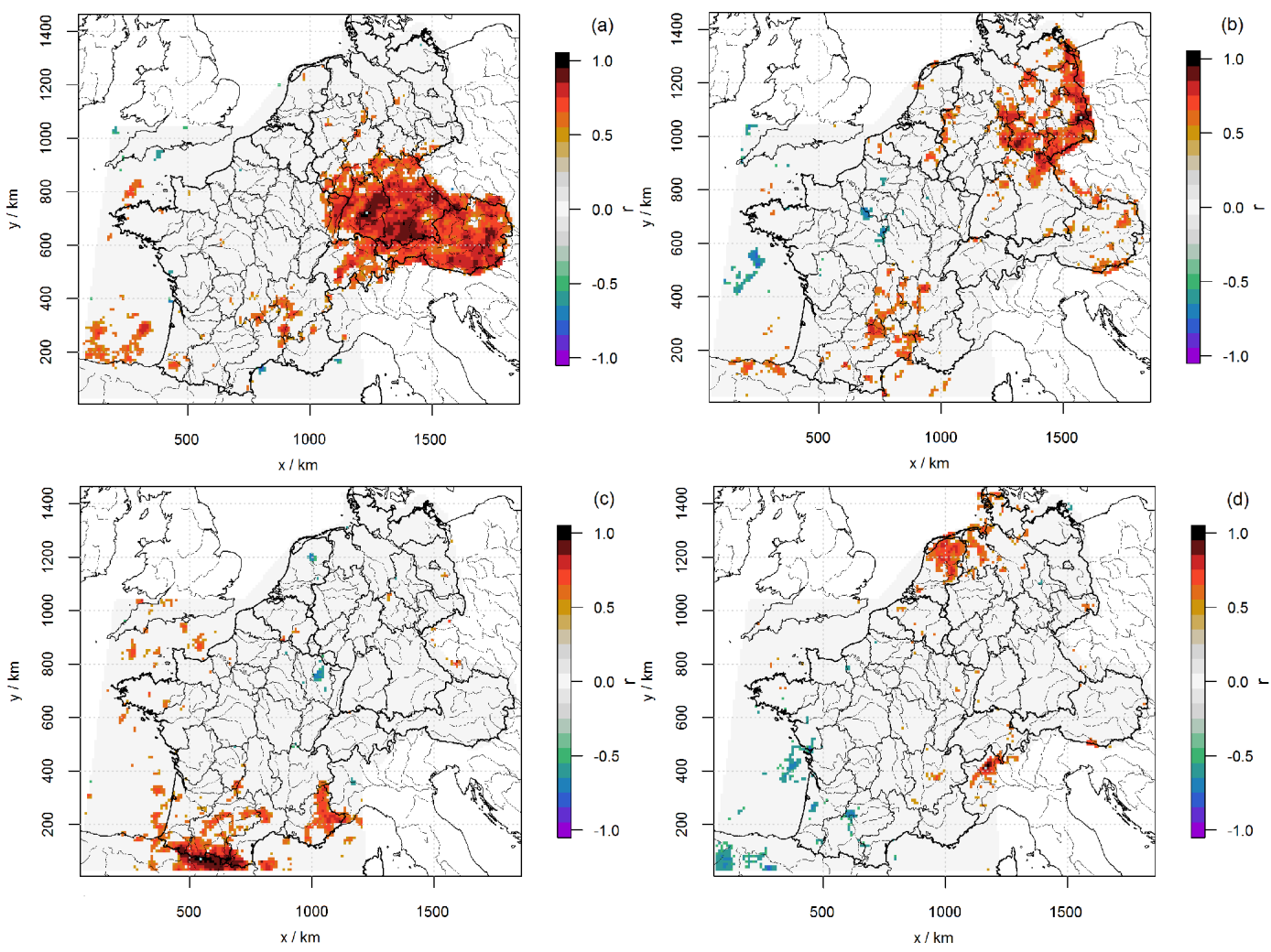

Figure 11. Spatial correlation (Spearman's coefficient $r_{\mathrm{S}}$ ) of the annual numbers of thunderstorm days with respect to different reference grid cells (indicated by a gray dot in each map) situated between the Black Forest and Swabian Jura (a), north of the Ore Mountains (b), on the southern side of the Pyrenees (c), and southwest of Ticino (d). Values that are not statistically significant $(\mathrm{Si}=95 \%)$ have been set to zero.

but also inside of a detached area basically comprising the Maritime Alps. By contrast, the correlation pattern obtained with respect to a location within the Ticino-Turin lightning maximum (Fig. 11d) features significant values only inside a closely confined region. In particular, there is no correlation even with large parts of the Ticino itself. Negative values are visible within a remote region, comprising for example grid points in northwestern Spain. The relatively large area in the Netherlands exhibiting significant positive values might be explained either by a complex spurious correlation or, more realistically, by random effects despite the high significance level employed.

From the examples shown in Fig. 11, it can be concluded that the large-scale flow configurations leading to convection-favoring conditions and sufficient lifting substantially differ among the various regions. For example, the relation of the temporal variability in TD numbers between the Pyrenees and the Maritime Alps points to a large relevance of weather types causing Mediterranean air to impinge on the respective mountain slopes. Strikingly, the latter region is not correlated with the nearby Ticino-Turin lightning maximum at all, where strong mesoscale correlation coefficient gradients show that even neighboring locations may behave inconsistently given a specific large-scale flow situ- ation prevailing, presumably due to the complex orography. Large correlations along the German-Polish border similar to the area of the local lightning maximum (Fig. 3) point to the influence of potentially instable air originating from the southeast in connection with the southern Polish lightning maximum addressed in Sect. 3.1. Flow patterns advecting warm and moist subtropical air masses to southern Germany, where they spread to the east and persist in a large region over a longer period of several days, might cause the interrelation of the time series in this area. However, low-level moisture and instability are also generated locally by means of evaporation and solar heating, yielding another contribution to the interannual variability observed. Note furthermore that convection may be triggered, in addition to large-scale lifting as discussed above, by processes taking place in the boundary layer and depending on local characteristics such as soil moisture and land use. For instance, Kotroni and Lagouvardos (2008) showed for the Mediterranean region that lightning activity is favored over woodland areas compared to places with little vegetation due to an increased soil moisture. Differentiating the impact of large-scale processes on interannual variability from those local factors might yield further insights. However, this aspect is beyond the scope of this paper. 

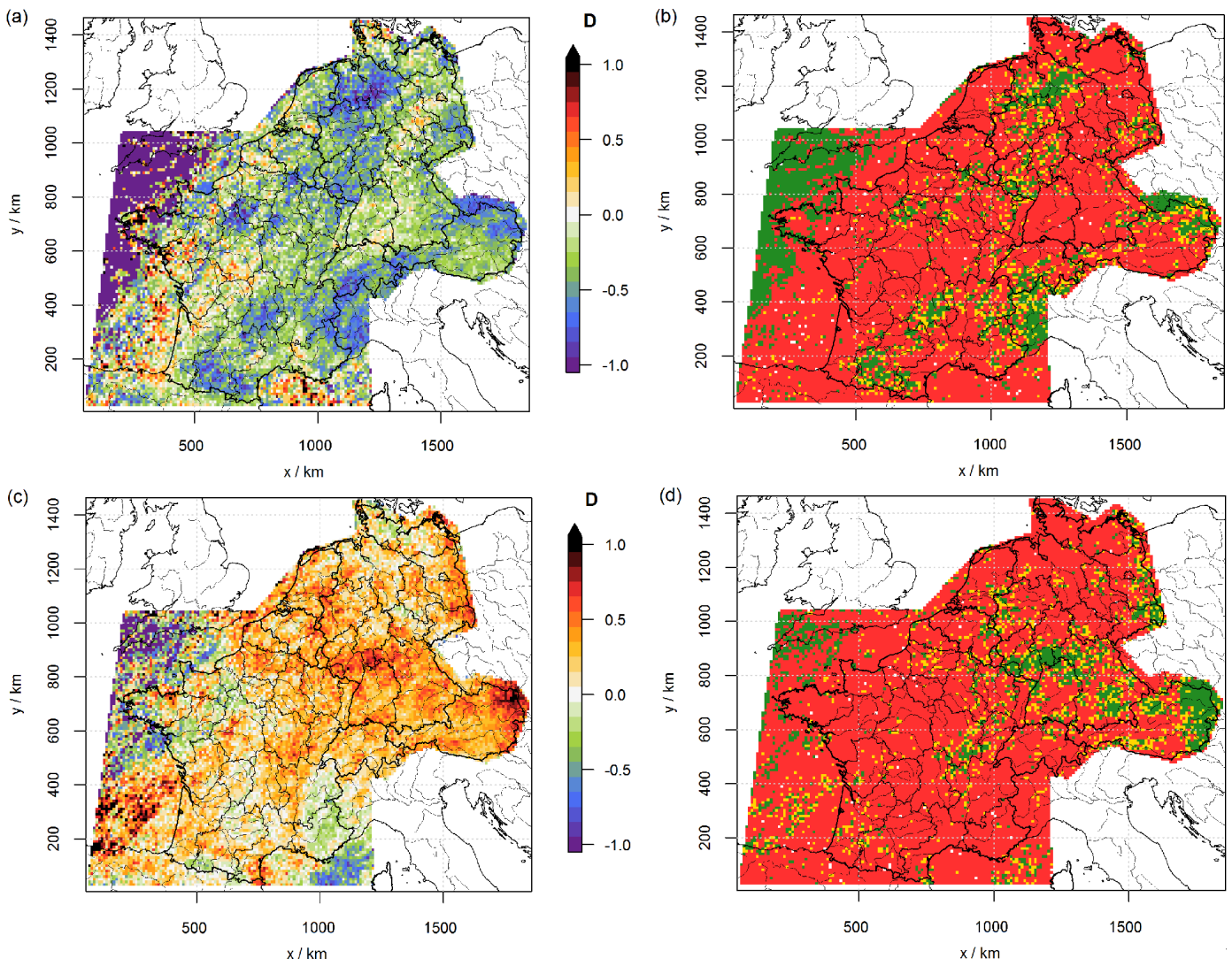

Figure 12. Relative deviation $(D)$ of the monthly number of thunderstorm days calculated with respect to months with an NAO index greater than $+1\left(N_{+}\right)$from that calculated with respect to all months $(\mathbf{a})$. Results of a bootstrap significance test with green/yellow grid boxes corresponding to areas where the null hypothesis has been rejected with $\mathrm{Si}=95 \%$ and $\mathrm{Si}=90 \%$, respectively, and red boxes denoting acceptance of null hypothesis (b). The same applies to $(\mathbf{c}, \mathbf{d})$, but $D$ is evaluated with respect to an NAO index below $-1\left(N_{-}\right)$.

\subsubsection{Relationship between convective activity and the NAO}

The complex characteristics of interannual variability found in the time series of TDs suggest investigating whether a systematic relation can be established between convective activity and atmospheric teleconnection patterns in terms of the NAO index, which is of relevance for European weather and climate (e.g., Della-Marta et al., 2007; Hurrell and Deser, 2010).

As can be clearly seen in Fig. 12, there is a distinct relation between NAO phases and lightning activity. Over most of the area, TD frequency is considerably increased during strongly negative NAO phases ( $N_{-}$; Fig. $12 \mathrm{c}$ and d). A prominent feature, for example, is the absolute maximum in eastern Austria, where TD frequency doubles in places $\left(D_{-}=1\right)$ compared to the entire sample. Statistically significant positive values of $D_{-}$are reached in several other areas, for example in the southern half of Germany and along the GermanPolish border. However, a sharply delineated zone of nearzero negative $D_{-}$values is located inside the margins of the French Alps, comprising all the mountain ranges between the Maritime Alps and Lake Geneva. Within a marine area, which can be perceived as a southward extension of this region, even significant negative values are observed.

Positive NAO phases $\left(N_{+}\right)$predominantly go along with a decrease of TD frequency (Fig. 12a and b). The most striking feature is a zone of strong reduction stretching from the Mediterranean coast in northwestern Italy along the French-Italian border northward to the upper Rhône Valley in Switzerland with an eastward extension to Grisons and Tyrol (see Fig. 1). Note that the Ticino-Turin lightning maximum situated in between is characterized by a weaker decrease. Other regions where $D_{+}$exhibits significantly negative values are the lower Danube Valley in northeastern Austria, the northern foreland of the Pyrenees, and parts of the North German Plain. The almost contiguous zone of highly significant results extending from the western Bay of Biscay to Cornwall suggests that the area-wide suppression of convection $\left(D_{+}=-1\right)$ is a reliable observation instead of a statistical artifact due to the small event sample sizes in that region. Comparing the locations of the $D_{+}$minima to the mean spatial pattern of TDs (Fig. 3) leads to the observation 

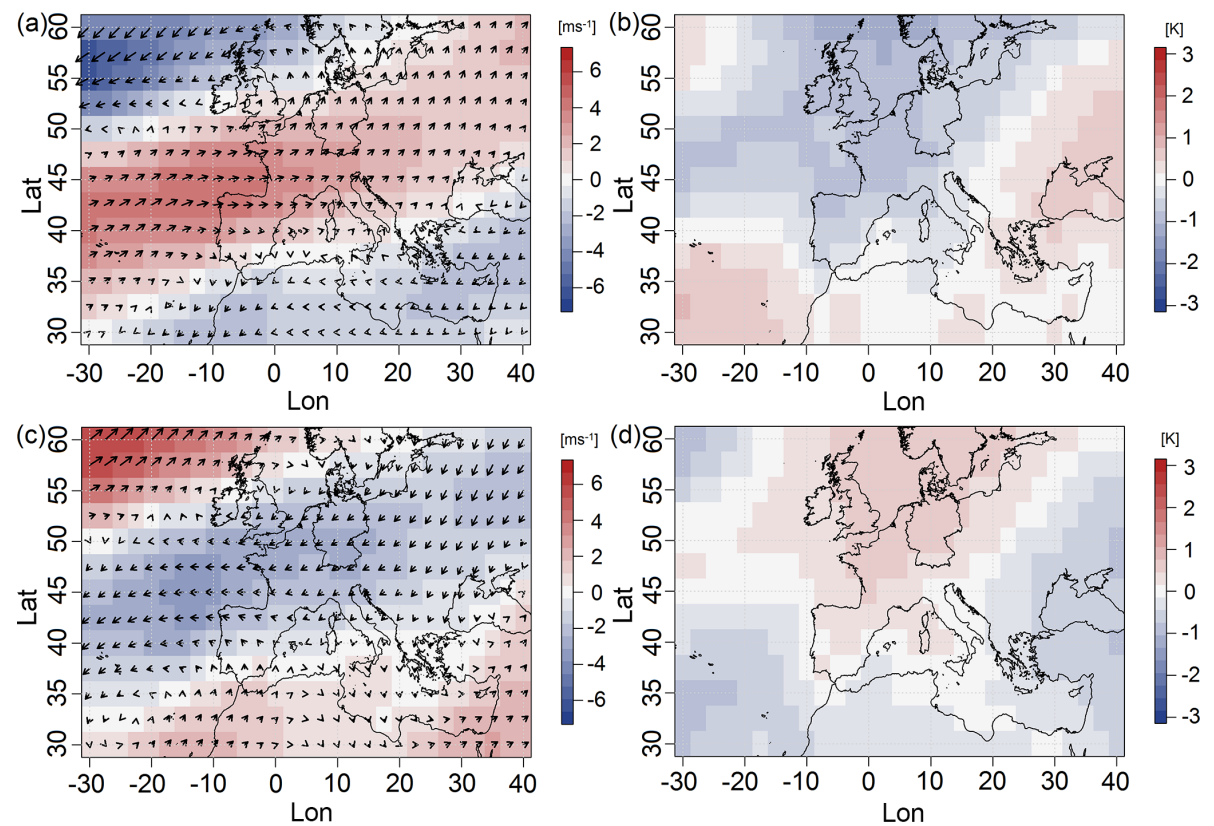

Figure 13. Average anomaly of (a) wind vector and horizontal velocity in $300 \mathrm{hPa}$, and (b) equivalent potential temperature $\theta_{\mathrm{e}}$ in $850 \mathrm{hPa}$ during negative NAO phases. $(\mathbf{c}, \mathbf{d})$ as $(\mathbf{a}, \mathbf{b})$, but for positive NAO phases.

that most of them are characterized by weak average convective activity.

Since the NAO index considered in this paper has been defined by the leading mode of a PCA performed separately for each month (see Sect. 2.1.2), the centers of action change their position throughout the year. Thus, we cannot interpret the positive NAO phase as a period of strong zonal flow in central Europe, as would be the case using the classical normalized pressure difference between two points. Instead, the southern center of action is given by a positive/negative anomaly band stretching from the United States to Europe when the NAO index is positive/negative, with its latitude oscillating between 30 and $35^{\circ} \mathrm{N}$ in winter between 40 and $50^{\circ} \mathrm{N}$ in summer (Barnston and Livezey, 1987; Hurrell and Deser, 2010). Consequently, during SHY, negative phases, $N_{-}$, go along with high geopotential gradients over southern central Europe, as shown by the anomaly pattern of the $300 \mathrm{hPa}$ wind field (Fig. 13a). Therefore, shortwave troughs frequently affect the investigation area and provide, primarily in the southern and eastern parts, quasi-geostrophic forcing, which is conducive to convection initiation. This mechanism might explain the increase in TD frequency connected to $N_{-}$. The contrary decrease of TD frequency over the French Alps confirms the exceptional nature of this lightning regime (see Sect. 3.2.1). In contrast, positive phases, $N_{+}$, correspond to a jet stream shifted to northern Europe (Fig. 13c) and, hence, a positive geopotential anomaly located over central Europe. The lack of lifting associated with this anomaly pattern explains the reduction of convective activity observed during $N_{+}$. Furthermore, strong capping inversions inside of deep high-pressure systems might additionally inhibit cell formation. Both factors seem to be detrimental especially in those areas where convective activity is low on average, such as over the marine areas around Brittany. Another example is the upper Rhône Valley, where ambient conditions have shaped up to be rarely conducive to convection due to shadowing effects (see Sect. 3.1), and a favorable flow pattern therefore is indispensable for thunderstorm development. In contrast, complex lifting mechanisms in nearby Ticino allow for convection in spite of the absence of large-scale forcing.

Additional insights into the relationship between convective activity and NAO can be gained by studying anomaly patterns of the equivalent potential temperature $\theta_{\mathrm{e}}$ at $850 \mathrm{hPa}$ for both $N_{+}$and $N_{-}$. Since high $\theta_{\mathrm{e}}$ values in the lower troposphere often go along with strong vertical $\theta_{\mathrm{e}}$ gradients equivalent to high levels of potential instability, $\theta_{\mathrm{e}}$ represents a suitable parameter for assessing the pre-convective environment (Piper et al., 2016). During $N_{-}$, the negative geopotential anomaly over large parts of Europe goes along with lower values of $\theta_{\mathrm{e}}$ (Fig. 13b). Hence, conditions over most of the investigation area are governed by air masses rather detrimental to thunderstorm formation from a thermodynamical point of view. This effect partly compensates for the convectionfavoring impact of the dynamical processes ahead of a trough (see Fig. 13a). During $N_{+}$, conversely, the positive geopotential anomaly that is associated with the northward displacement of the jet stream (see Fig. 13c) implies a pronounced increase in $\theta_{\mathrm{e}}$ over the entire investigation area (Fig. 13d). Consequently, $N_{+}$yields favorable thermodynamical conditions for thunderstorm formation, but the simultaneous lack 
of large-scale forcing mechanisms in combination with convection suppression due to large-scale subsidence leads to the decrease of TD numbers observed in many regions. However, convective activity may even be enhanced during $N_{+}$, when local-scale lifting is present, such as convergence zones inside of the boundary layer. Indeed, some areas in western France exhibit positive values of $D_{+}$that might be related to this effect. Hence, the impact of the NAO on convective activity is governed by the modification of both thermodynamical and dynamical conditions relevant for the formation of thunderstorms.

\section{Conclusions}

The spatiotemporal variability of convective activity has been investigated within a study domain comprising large parts of central and western Europe based on 14 years of lightning data (April-September). For this purpose, we developed an objective definition of the dichotomous variable thunderstorm day, which is robust in the case of single severe events and simultaneously neglects small-scale weak thunderstorms. We studied the mean spatial distribution of annual TD numbers, compared diurnal and seasonal cycles of lightning incidence among several European subregions, and performed analyses of interannual variability. In particular, the impact of the NAO on convective activity was investigated, as it represents the dominant low-frequency mode of the large-scale flow configuration.

It was found that the mean spatial pattern of thunderstorm activity is characterized by a pronounced northwestto-southeast gradient between very low values $(\sim 2$ TDs per year) observed in northwestern France and strong maxima ( $\sim 21$ TDs) in some parts of the southern Alps, for instance in the Swiss canton of Ticino. Superimposed on this largescale trend are several distinct regional structures such as the pronounced lightning minima over the deepest Alpine valleys. Seasonality is characterized by a single maximum in July in most places. However, the area of maximum convective activity moves in a southwestward direction from southeastern Austria in April to the surroundings of Ticino in July. On the French Mediterranean coast, contrarily, thunderstorm activity does not reach its maximum until September. Regional diurnal cycles of flash frequency mostly exhibit a single afternoon or evening maximum, with its exact time varying substantially. Distinct spatial differences are present regarding the occurrence of nighttime thunderstorms. Moreover, most diurnal cycles feature pronounced seasonal changes, such as along Côte d'Azur in September, when a transition takes places from a regime dominated by a weak afternoon maximum to frequent nighttime lightning.

Multiannual TD time series are spatially interrelated to a limited extent only. Correlation maps show that the area exhibiting a high and significant degree of correlation varies strongly in size for different reference points, and can be ex- tremely small in some cases. The NAO has a significant impact on lightning probability with its negative/positive phase generally favoring/reducing convective activity. In some areas, the strength of this effect depends on the orographic structures prevailing.

Three main factors governing the spatiotemporal variability as described above are given by the variable distance to marine areas, local orographic features leading to flow deviations and, consequently, convergence zones, and regional differences in the abundance of low-level moisture. During the summer half-year, the Atlantic, North Sea, and Baltic Sea represent sinks of low-level sensible heat stabilizing the atmospheric boundary layer. The Mediterranean, however, additionally provides a source of latent heat due to the higher temperatures prevailing. Therefore, thunderstorms are inhibited over the Mediterranean coastal zone during summer, while they are promoted farther inland, where the humid air impinges on the Alps. In September, the Mediterranean has become warm relative to the air leading to more unstable conditions over the water, also during nighttime. Complex local flow patterns in combination with moist low-level air allow for distinct convective maxima along the Alps and some low mountain ranges, for example downstream of the Black Forest. The local orographic structures also affect the degree of convective organization relevant in the context of diurnal cycles, as long-lived convective systems often are responsible for substantial nighttime activity. However, thunderstorm activity diminishes strongly, where orographic shadowing effects imply a reduction of moisture. Differing humidity levels along the southern Alpine range during early summer cause the shift of the peak convective area observed in this region.

The analysis of interannual variability shows that the steering factors of convective activity described above are not sufficient in order to explain some of the aspects observed. Instead, time series of annual lightning incidence seem to depend on specific large-scale drivers prevailing frequently in some years and inducing the advection of unstable air and lifting at higher tropospheric levels in those regions, where high TD numbers are observed. Our results suggest that different large-scale conditions might favor convection in the various subregions. The substantial impact of the NAO has to be discussed by considering dynamical and thermodynamical aspects separately. On the one hand, negative NAO phases are connected to flow patterns that are associated with frequent shortwave troughs providing lifting over central $\mathrm{Eu}-$ rope, whereas during positive phases a positive geopotential anomaly tends to suppress convection due to a lack of largescale lifting. On the other hand, negative phases go along with a pronounced reduction of $\theta_{\mathrm{e}}$ at $850 \mathrm{hPa}$ over most of the investigation area, which is detrimental to convective activity, while a positive $\theta_{\mathrm{e}}$ anomaly is present during positive phases. Hence, the thermodynamical effects of the NAO phases on convective activity partly compensate for the dynamical effects. Due to pronounced seasonal variations of the 
NAO pattern, the features discussed above are characteristic for the summer half-year only.

A potential weakness of our research is that the 14-year time series of lightning data does not reach the climatological time range. However, this sample should be sufficient for reliable analyses regarding spatiotemporal variability on diurnal and seasonal timescales. As opposed to earlier studies, which all are based on shorter time spans, we were able to additionally investigate multiannual modes of variability using well-suited significance tests in order to ensure that no misleading conclusions are drawn due to the limited sample size. Furthermore, the analyses presented in this paper focus on CG lightning only. In fact, present-day LF location systems are capable of detecting IC lightning as well. For instance, Marra et al. (2017) studied IC activity within a strong convective cell using LF data. However, multiannual statistical analyses regarding IC lightning suffer from a significant reduction of both detection efficiency and location accuracy compared to CG lightning (Schulz et al., 2014). Although an IC climatology might potentially reflect further meteorological aspects, we therefore decided to neglect IC lightning. A further interesting issue is the spatiotemporal variability of winter lightning, particularly in light of the connections between thunderstorm genesis in marine regions and the seasonal variations of the temperature difference between water and air. However, much longer time series would be necessary for statistically reliable studies of winter lightning due to the small event samples.

The clear and significant impact of the NAO pattern on convective activity in Europe motivates us to scrutinize the crucial role of large-scale flow in future research. The objective is to gain further insight into the physics behind the complex spatiotemporal variability discussed in this paper. This involves evaluating additional teleconnection modes obtained by Barnston and Livezey (1987) such as the east Atlantic pattern. To generate longer, multidecadal time series allowing for further investigations such as trend and spectral analysis, we have additionally implemented objective weather types as indicators for a high convective predisposition (Piper et al., 2016).

Data availability. Lightning data (EUCLID) are not freely available but can be requested from Siemens BLIDS (http://blids. de). Teleconnection index data are provided by NOAA and can be downloaded from http://www.cpc.ncep.noaa.gov/data/teledoc/ telecontents.shtml. NCEP/NCAR1 reanalysis data are available for download at https://www.esrl.noaa.gov/psd/data/gridded/data.ncep. reanalysis.html.

Competing interests. The authors declare that they have no conflict of interest.
Acknowledgements. Funding by the Helmholtz Climate Initiative REKLIM (Regional Climate Change), a joint research project of the Helmholtz Association of German Research Centres (HGF), is gratefully acknowledged. We gratefully thank Siemens AG for providing lightning data and NOAA for providing NAO data. We acknowledge support from the Open Access Publishing Fund of KIT. We thank the two reviewers for their comments, which helped to improve the quality of the paper.

The article processing charges for this open-access publication were covered by a Research Centre of the Helmholtz Association.

Edited by: Giulia Panegrossi

Reviewed by: Kostas Lagouvardos and one anonymous referee

\section{References}

Anderson, G. and Klugmann, D.: A European lightning density analysis using 5 years of ATDnet data, Nat. Hazards Earth Syst. Sci., 14, 815-829, https://doi.org/10.5194/nhess-14-815-2014, 2014.

Antonescu, B. and Burcea, S.: A cloud-to-ground lightning climatology for Romania, Mon. Weather Rev., 138, 579-591, 2010.

Barnston, A. G. and Livezey, R. E.: Classification, seasonality and persistence of low-frequency atmospheric circulation patterns, Mon. Weather Rev., 115, 1083-1126, 1987.

Bedka, K. M.: Overshooting cloud top detections using MSG SEVIRI Infrared brightness temperatures and their relationship to severe weather over Europe, Atmos. Res., 99, 175-189, https://doi.org/10.1016/j.atmosres.2010.10.001, 2011.

Beirle, S., Koshak, W., Blakeslee, R., and Wagner, T.: Global patterns of lightning properties derived by OTD and LIS, Nat. Hazards Earth Syst. Sci., 14, 2715-2726, https://doi.org/10.5194/nhess-14-2715-2014, 2014.

Bertram, I.: Verbreitung und Verlagerung von Gewittern in Österreich, diploma thesis, Leopold-Franzens-Universität Innsbruck, 2000.

Bissolli, P., Grieser, J., Dotzek, N., and Welsch, M.: Tornadoes in Germany 1950-2003 and their relation to particular weather conditions, Global Planet. Change, 57, 124-138, 2007.

Brooks, H. E., Lee, J. W., and Craven, J. P.: The spatial distribution of severe thunderstorm and tornado environments from global reanalysis data, Atmos. Res., 67, 73-94, 2003.

Cacciamani, C., Battaglia, F., Patruno, P., Pomi, L., Selvini, A., and Tibaldi, S.: A climatological study of thunderstorm activity in the Po Valley, Theor. Appl. Climatol., 50, 185-203, 1995.

Cecil, D. J. and Blankenship, C. B.: Toward a global climatology of severe hailstorms as estimated by satellite passive microwave imagers, J. Climate, 25, 687-703, 2012.

Cehak, K.: Zur Gewitter- und Hagelklimatologie von Österreich, Ver. Schweizer Meteorol. Anstalt, 40, 316-319, 1980.

Christian, H. J., Blakeslee, R. J., Boccippio, D. J., Boeck, W. L., Buechler, D. E., Driscoll, K. T., Goodman, S. J., Hall, J. M., Koshak, W. J., Mach, D. M., and Stewart, M. F.: Global frequency and distribution of lightning as observed from space by the Optical Transient Detector, J. Geophys. Res.-Atmos., 108, 
ACL 4-1-ACL 4-15, https://doi.org/10.1029/2002JD002347, 2003.

Coquillat, S., Boussaton, M.-P., Buguet, M., Lambert, D., Ribaud, J.-F., and Berthelot, A.: Lightning ground flash patterns over Paris area between 1992 and 2003: Influence of pollution?, Atmos. Res., 122, 77-92, 2013.

Costa, S., Mezzasalma, P., Levizzani, V., Alberoni, P., and Nanni, S.: Deep convection over Northern Italy: synoptic and thermodynamic analysis, Atmos. Res., 56, 73-88, 2001.

Czernecki, B., Taszarek, M., Kolendowicz, L., and Konarski, J.: Relationship between human observations of thunderstorms and the PERUN lightning detection network in Poland, Atmos. Res., 167, 118-128, 2016.

Della-Marta, P., Luterbacher, J., Von Weissenfluh, H., Xoplaki, E., Brunet, M., and Wanner, H.: Summer heat waves over western Europe 1880-2003, their relationship to large-scale forcings and predictability, Clim. Dynam., 29, 251-275, 2007.

Finke, U. and Hauf, T.: The characteristics of lightning occurrence in southern Germany, Beitr. Phys. Atmosph., 69, 361-374, 1996.

Fuhrer, O. and Schär, C.: Embedded cellular convection in moist flow past topography, J. Atmos. Sci., 62, 2810-2828, 2005.

Gladich, I., Gallai, I., Giaiotti, D., and Stel, F.: On the diurnal cycle of deep moist convection in the southern side of the Alps analysed through cloud-to-ground lightning activity, Atmos. Res., 100, 371-376, 2011.

Haklander, A. J. and van Delden, A.: Thunderstorm predictors and their forecast skill for the Netherlands, Atmos. Res., 67-68, 273299, 2003.

Holt, M., Hardaker, P., and McLelland, G.: A lightning climatology for Europe and the UK, 1990-99, Weather, 56, 290-296, 2001.

Hosking, J. R.: L-moments: analysis and estimation of distributions using linear combinations of order statistics, J. Roy. Stat. Soc. B, 52, 105-124, 1990.

Hurrell, J. W. and Deser, C.: North Atlantic climate variability: the role of the North Atlantic Oscillation, J. Mar. Syst., 79, 231-244, 2010.

Junghänel, T., Brendel, C., Winterrath, T., and Walter, A.: Towards a radar-and observation-based hail climatology for Germany, Meteorol. Z., 25, 435-445, 2016.

Kalnay, E., Kanamitsu, M., Kislter, R. C. W., Deaven, D., Gandin, L., Iredell, M., Saha, S., White, G., Woollen, J., Zhu, Y., Leetmaa, A., Reynolds, F., Chelliah, M., Ebisuzaki, W., Higgins, W., J. J., Mo, K., Ropelewski, C. W. J., Jenne, F., and Joseph, D.: The NCEP/NCAR 40-year reanalysis project, B. Am. Meteorol. Soc., 77, 437-471, 1996.

Kohn, W.: Statistik: Datenanalyse und Wahrscheinlichkeitsrechnung, Springer-Verlag, Berlin, 2006.

Kotroni, V. and Lagouvardos, K.: Lightning occurrence in relation with elevation, terrain slope, and vegetation cover in the Mediterranean, J. Geophys. Res.-Atmos., 113, D21118, https://doi.org/10.1029/2008JD010605, 2008.

Kotroni, V. and Lagouvardos, K.: Lightning in the Mediterranean and its relation with sea-surface temperature, Environ. Res. Lett., 11, 034006, https://doi.org/10.1088/17489326/11/3/034006, 2016.

Kunz, M.: The skill of convective parameters and indices to predict isolated and severe thunderstorms, Nat. Hazards Earth Syst. Sci., 7, 327-342, https://doi.org/10.5194/nhess-7-327-2007, 2007.
Kunz, M. and Puskeiler, M.: High-resolution assessment of the hail hazard over complex terrain from radar and insurance data, Meteorol. Z., 19, 427-439, 2010.

Kunz, M., Sander, J., and Kottmeier, C.: Recent trends of thunderstorm and hailstorm frequency and their relation to atmospheric characteristics in southwest Germany, Int. J. Climatol., 29, 2283 2297, https://doi.org/10.1002/joc.1865, 2009.

Lassègues, P., Vincendon, B., Moisselin, J., Minguet, D., and Poignet, J.: Étude Climatologique Des Événements Foudre Et Détermination d'Une Échelle d'Intensité, Publication de l'Association Internationale de Climatologie, 15, 243-250, 2003.

Lee, W.-C. and Rodgers, J. L.: Bootstrapping correlation coefficients using univariate and bivariate sampling, Psycholog. Meth., 3, 91-103, 1998.

Maiwald, H. and Schwarz, J.: Der Tornado von Bützow in Mecklenburg-Vorpommern - Ingenieuranalyse der Gebäudeschäden, Bautechnik, 93, 254-264, 2016.

Manoochehrnia, P., Rachidi, F., Rubinstein, M., and Schulz, W.: Lightning statistics in Switzerland, in: 9th International Symposium on Lightning Protection (SIPDA), 26-30 November 2007, Foz Do Iguaçu, Brazil, 2007.

Marra, A., Porcù, F., Baldini, L., Petracca, M., Casella, D., Dietrich, S., Mugnai, A., Sanò, P., Vulpiani, G., and Panegrossi, G.: Observational analysis of an exceptionally intense hailstorm over the Mediterranean area: Role of the GPM Core Observatory, Atmos. Res., 192, 72-90, 2017.

Mohr, S. and Kunz, M.: Recent trends and variabilities of convective parameters relevant for hail events in Germany and Europe, Atmos. Res., 123, 211-228, https://doi.org/10.1016/j.atmosres.2012.05.016, 2013.

Mohr, S., Kunz, M., and Geyer, B.: Hail potential in Europe based on a regional climate model hindcast, Geophys. Res. Lett., 42, 10904-10912, https://doi.org/10.1002/2015GL067118, 2015.

Morel, C. and Senesi, S.: A climatology of mesoscale convective systems over Europe using satellite infrared imagery. II: Characteristics of European mesoscale convective systems, Q. J. Roy. Meteorol. Soc., 128, 1973-1995, 2002.

Morris, R. M.: The Spanish plume-testing the forecaster's nerve, Meteorol. Mag., 115, 349-357, 1986.

Nisi, L., Martius, O., Hering, A., Kunz, M., and Germann, U.: Spatial and temporal distribution of hailstorms in the Alpine region: a long-term, high resolution, radar-based analysis, Q. J. Roy. Meteorol. Soc., 142, 1590-1604, 2016.

Novák, P. and Kyznarová, H.: Climatology of lightning in the Czech Republic, Atmos. Res., 100, 318-333, 2011.

Pelz, J.: Die geographische Verteilung der Tage mit Gewitter in Mitteleuropa, Beilage zur Berliner Wetterkarte, 48, 1-32, 1984.

Peyraud, L.: Analysis of the 18 July 2005 Tornadic Supercell over the Lake Geneva Region, Weather Forecast., 28, 1524-1551, 2013.

Piper, D., Kunz, M., Ehmele, F., Mohr, S., Mühr, B., Kron, A., and Daniell, J.: Exceptional sequence of severe thunderstorms and related flash floods in May and June 2016 in Germany - Part 1: Meteorological background, Nat. Hazards Earth Syst. Sci., 16, 2835-2850, https://doi.org/10.5194/nhess-16-2835-2016, 2016.

Pohjola, H. and Mäkelä, A.: The comparison of GLD360 and EUCLID lightning location systems in Europe, Atmos. Res., 123, 117-128, 2013. 
Punge, H. and Kunz, M.: Hail observations and hailstorm characteristics in Europe: A review, Atmos. Res., 176-177, 159-184, https://doi.org/10.1016/j.atmosres.2016.02.012, 2016.

Punge, H., Werner, A., Bedka, K., and Kunz, M.: A new physically based stochastic event catalogue for hail in Europe, Nat. Hazards, 73, 1625-1645, 2014.

Puskeiler, M., Kunz, M., and Schmidberger, M.: Hail Statistics for Germany derived from SinglePolarization Radar Data, Atmos. Res., 178-179, 459-470, https://doi.org/10.1016/j.atmosres.2016.04.014, 2016.

Richman, M. B.: Rotation of principal components, J. Climatol., 6, 293-335, 1986.

Santos, J. A., Reis, M. A., Sousa, J., Leite, S. M., Correia, S., Janeira, M., and Fragoso, M.: Cloud-to-ground lightning in Portugal: patterns and dynamical forcing, Nat. Hazards Earth Syst. Sci., 12, 639-649, https://doi.org/10.5194/nhess-12-639-2012, 2012.

Santos, J. A., Reis, M. A., Pablo, F. D., Rivas-Soriano, L., and Leite, S. M.: Forcing factors of cloud-to-ground lightning over Iberia: regional-scale assessments, Nat. Hazards Earth Syst. Sci., 13, 1745-1758, https://doi.org/10.5194/nhess-13-1745-2013, 2013.

Schulz, W. and Diendorfer, G.: EUCLID network performance and data analysis, in: Proceedings of the 17th International Lightning Detection Conference (ILDC), Tucson, AZ, 2002.

Schulz, W., Cummins, K., Diendorfer, G., and Dorninger, M.: Cloud-to-ground lightning in Austria: A 10-year study using data from a lightning location system, J. Geophys. Res.-Atmos., 110, D09101, https://doi.org/10.1029/2004JD005332, 2005.
Schulz, W., Pedeboy, S., Vergeiner, C., Defer, E., and Rison, W.: Validation of the EUCLID LLS during HyMeX SOP1, in: International Lightning Detection Conference ILDC, 1819 March 2014, Tucson, USA, 2014.

Schulz, W., Diendorfer, G., Pedeboy, S., and Poelman, D. R.: The European lightning location system EUCLID - Part 1: Performance analysis and validation, Nat. Hazards Earth Syst. Sci., 16, 595-605, https://doi.org/10.5194/nhess-16-595-2016, 2016.

Soriano, L. R., De Pablo, F., and Tomas, C.: Ten-year study of cloud-to-ground lightning activity in the Iberian Peninsula, J. Atmos. Sol.-Terr. Phy., 67, 1632-1639, 2005.

Van Delden, A.: The synoptic setting of a thundery low and associated prefrontal squall line in western Europe, Meteorol. Atmos. Phys., 65, 113-131, 1998.

Van Delden, A.: The synoptic setting of thunderstorms in Western Europe, Atmos. Res., 56, 89-110, 2001.

Wakonigg, H.: Witterung und Klima in der Steiermark, Verlag für d. Techn. Univ. Graz, Graz, 1978.

Wapler, K.: High-resolution climatology of lightning characteristics within Central Europe, Meteorol. Atmos. Phys., 122, 175-184, 2013.

Wilks, D. S.: Statistical methods in the atmospheric sciences, Academic Press, San Diego, 1995.

WMO: Manual on Codes, available at: http://www.wmo.int/pages/ prog/www/WMOCodes/WMO306_vI1/VolumeI.1.html (last access: August 2017), 2016. 